\title{
Thermal study of a transport container
}

\author{
J. Rodríguez-Bermejo ，P. Barreiro ，J.I. Robla ，L. Ruiz-García \\ Sensors Technology Laboratory, National Center for Metallurgical Research. Spanish Council for Scientific Research \\ (CENIM-CSIC). Madrid 28040, Spain \\ Physical Properties Laboratory, Advanced Techniques in Agro-food (LPF-TAG), Polytechic University of Madrid (UPM), Madrid 28040, Spain
}

\begin{abstract}
A thermal study of a container for international transport has been carried out in order to determine the temperature distributions. Several experimental conditions such as cooling modes, the onset of defrosting, the existence of cargo inside the container and two varying set points have been evaluated. It was observed that the difference between the temperature inside the container and the set point raised up to $30 \%$ of ambient temperature. Moreover, it was observed that the modulated cooling allowed to obtain a more homogeneous refrigeration. However, temperature differences up to $8{ }^{\circ} \mathrm{C}$ were observed under on off control cooling.
\end{abstract}

Keywords: Container; Sensor; Cooler performance modes; Defrosting; Airflow; Temperature distributions; Modelling; Refrigerated transport

\section{Introduction}

The study of temperature gradients inside refrigeration rooms and containers, is a critical topic for the industry. Cooling inhibits the growth of decay-producing micro organisms and restricts enzymatic and respiratory activities during the postharvest period, prevents water loss by facilitating high air humidity, reduces ethylene production and also decreases the sensitivity of products to ethylene (Dinçer, 2003).

Some empirical researches have been focused on the study of thermal variations and airflow during long distance journey. Thus, Tanner and Amos (2003a) carried out several experiments in order to determine the spatialtemporal thermal variations during a trip from $\mathrm{Ncw}$ Zcaland to Belgium. Twenty pallets of fruit were monitored by means of thermocouples in order to gather temperature data. Pallets were placed into a refrigerated hold of a vessel and transported from New Zealand to Belgium. The results showed that there was a significant variability both spatially across the width of the container and as well as all along the trip. In another study of Tanner and Amos (2003b), the effect of temperature differences on firmness cvolution of several kiwifruit cargos was performed. This study showed that temperatures inside the container were above the recommended storage range leading to an acceleration in the loss of firmness. Similarly, Moureh, Menia, and Flick (2002) and Moureh and Flick (2004) concluded that pressure and temperature gradients inside a transport container are a consequence of the existence of airflow patterns throughout loaded refrigerated vehicle enclosures (RVE). They tested conventional ventilation with regard to an air-duct system and concluded that overall the homogeneity of the ventilation inside a 1:3 scalcd truck avoids the occurrence of stagnant zones and low velocitics in the rear part of the load. The proposed air-duct system enabled them to maintain the air speed in such zones at around $1 \mathrm{~m} / \mathrm{s}$ instead of $0.1 \mathrm{~m} / \mathrm{s}$, an average value for conventional ventilation. These results are congruent with that of Lindqvist $(1998,1999)$ who used an experimental approach to measure pressure inside a full-scale laboratory model of a reefer, concluding that the high pressure gradients were 
measured in the front of the vessel while the low pressure ones were observed in the rear.

More on a theoretical basis, many studies are ongoing in order to improve analytical models of cooling systems, such as refrigeration rooms or containers. In this context, Computational Fluid Dynamics (CFD) tools for solving the Navier-Stokes equations are widely used as stated in several recent review papers (Scott \& Richardson, 1997; Wang \& Sun, 2003; Xia \& Sun, 2002). There are also many recent works on the applications of CFD to cold storage of perishable products (Nahor, Hoang, Verboven, Baelmans, \& Nicolaï, 2004; Verboven, Hoang, Baelmans, \& Nicolaï, 2004; Xie, Qu, Shi, \& Sun, 2006). Some of these experiments have been developed for studying the pressure drops through batches of apples and chicory roots (Verboven et al., 2004). Pressure drop results were correlated with the Darcy-Forchheimer equations and the confinement parameters were determined by means of CFD simulations. In this study, it was found that there were variations in the pressure drop throw beds of the product due to the existence of differences in the shape, surface roughness and confinement of the package. In another study (Verboven, Hoang, \& Nicolaï, 2003), empty cool rooms for agricultural commodities were studied by means of CFD in order to compare several turbulence models for predicting the air flow rate in cool rooms. It was concluded that when the containers or cool rooms have an improper design, local differences in cold air may occur, which derive into temperature gradients, relative humidity, changes in air velocity and turbulence intensity.

Recently mathematic models have been proposed for characterizing scaled refrigeration rooms (Xie et al., in press). These authors observed that several design parameters such as the corner baffle and the stack mode of foodstuffs, had effect on the airflow. Furthermore, Hoang, Verboven, Baelmans, and Nicolaï (2004) developed a transient two-phase air-product model of heat and mass transfer processes in order to study the effects of process parameters and product properties on the product temperature and weight loss during cooling and storage of chicory roots in bulks. They concluded that the product temperature during storage showed to be mostly sensitive to variations in air velocity, temperature and bulk porosity, which is congruent with results found at the empirical research.

One of the outcomes that is expected from having a deeper knowledge on refrigeration processes is the decrease on energy requirements which is a mandatory issue according to the white book of European Transport (European Commission, 2001). Improvements in the control strategies for cold storage chambers and reefers will be a main task for increasing energy savings. Recent studies are exploring the subject. Keesman, Diederik, and Lukasse (2003) carried out a work which main goal was to simplify a simulation method, considering the temperature and water content in quasi-steady state and introducing real-time forecasts for controlling the storage conditions in order to minimize the loss of quality and to optimise energy consumption.
The results show that the incorporation of forecasts reduced highly the ventilation costs while maintaining quality levels.

In this work, a thermal study of a multi compartment reefer 20 type container is developed in order to characterize several work conditions: cooling mode (modulated and off/on control), set point $\left(0^{\circ} \mathrm{C}\right.$ and $\left.6^{\circ} \mathrm{C}\right)$, defrosting system and load level. Also, the outer ambient temperatures are evaluated.

\section{Materials and methods}

The experiments were carried out inside a multi compartment reefer 20, available at the National Centre for Metallurgical Research (CENIM-CSIC), which dimensions are $6058 \times 2438 \times 2591 \mathrm{~mm}$. The container was divided into two compartments, separated by an isolated wall. The internal dimensions of the smaller compartment were $2620 \times 2184 \times 2270 \mathrm{~mm}$. The cooler, located at the top of the small compartment, enabled it to perform under two modes of work: modulated cooling and off/on control cooling. Both performance modes will be identified as modulated and off/on control modes, respectively. Some of the cooler technical features were: $3825 \mathrm{~W}$ power at $-20^{\circ} \mathrm{C}$; $6765 \mathrm{~W}$ power at $0{ }^{\circ} \mathrm{C} ; 2200 \mathrm{~m}^{3} \mathrm{~h}^{-1}$ air flow; $200 \mathrm{~cm}^{3}$ cylinder capacity and on-off defrosting cycles, among others. All tests were performed inside the smallest compartment, while in the larger one, data acquisition equipments were placed. The experiments consisted of registering temperature measurements both inside and outside the container, in order to assess the temperature distribution under available cooler work modes: modulated and off/on control. Several set point temperatures were also programmed on the container digital display $\left(0^{\circ} \mathrm{C}\right.$ and $\left.6^{\circ} \mathrm{C}\right)$ together with two cargo levels: empty and almost full $\left(720 \mathrm{~kg} / \mathrm{m}^{3}\right)$. Finally, systematic (every $6 \mathrm{~h}$ ) or automatic defrosting was set depending on the experiment.

\subsection{Temperature measurements}

Inside the container, temperature measurements were taken by means of 4-wires Pt100 (RTD sensors). A maximum number of 68 sensors were situated inside the smaller compartment on the walls, in the ceiling and on the floor by means of a grid. Additionally, one Pt 100 was located in the geometrical centre of the compartment (GCS). In total, a maximum number of 69 temperature sensors were used for gathering temperature data inside the smaller container compartment depending on the experiment (see Table 1), since two more Pt 100 sensors were situated outside the container concerning the ambient sensors. One of the ambient sensors was located on the roof of the container (sunny side) while the other was placed under the container (shade), except for the first and second experiments where both were located on the sunny side. The main objective of such ambient configuration was to measure the temperature as affected by the direct radiation compared to that of 
Table 1

Experimental conditions for experiments: $C$. modulated performance; NC, off/on control performance; state of cargo ( $\mathbf{E}_{\text {; }}$ empty: L. loaded)

\begin{tabular}{|c|c|c|c|c|c|c|c|c|}
\hline Test & 1 & 2 & 3 & 4 & 5 & 6 & 7 & 8 \\
\hline Date & $\begin{array}{l}11-14 \\
\text { March }\end{array}$ & $\begin{array}{l}18-22 \\
\text { March }\end{array}$ & $\begin{array}{l}22-25 \\
\text { April }\end{array}$ & $\begin{array}{l}29-2 \\
\text { May }\end{array}$ & $\begin{array}{l}30-3 \\
\text { October }\end{array}$ & $\begin{array}{l}3-6 \\
\text { October }\end{array}$ & $\begin{array}{l}21-27 \\
\text { October }\end{array}$ & $\begin{array}{l}4-7 \\
\text { November }\end{array}$ \\
\hline $\begin{array}{c}\text { Set point } \\
\text { Cargo } \\
\text { Cooler }\end{array}$ & $\begin{array}{l}0^{\circ} \mathrm{C} \\
\mathrm{E} \\
\mathrm{C}\end{array}$ & $\begin{array}{l}0^{\circ} \mathrm{C} \\
\mathrm{E} \\
\mathrm{NC}\end{array}$ & $\begin{array}{l}6^{\circ} \mathrm{C} \\
\mathbf{E} \\
\mathrm{NC}\end{array}$ & $\begin{array}{l}6^{\circ} \mathrm{C} \\
\mathrm{E} \\
\mathrm{C}\end{array}$ & $\begin{array}{l}6^{\circ} \mathrm{C} \\
\mathrm{L} \\
\mathrm{NC}\end{array}$ & $\begin{array}{l}6^{\circ} \mathrm{C} \\
\mathrm{L} \\
\mathrm{C}\end{array}$ & $\begin{array}{l}0^{\circ} \mathrm{C} \\
\mathrm{L} \\
\mathrm{NC}\end{array}$ & $\begin{array}{l}0^{\circ} \mathrm{C} \\
\mathrm{L} \\
\mathrm{C}\end{array}$ \\
\hline $\begin{array}{c}\text { No. sensor } \\
\text { Ceiling } \\
\text { Walls } \\
\text { Floor } \\
\text { GCS }\end{array}$ & $\begin{array}{l}6 \\
48 \\
- \\
-\end{array}$ & $\begin{array}{l}6 \\
48 \\
- \\
1\end{array}$ & $\begin{array}{l}6 \\
48 \\
- \\
1\end{array}$ & $\begin{array}{l}6 \\
48 \\
- \\
1\end{array}$ & $\begin{array}{l}6 \\
51 \\
10 \\
1\end{array}$ & $\begin{array}{l}6 \\
51 \\
10 \\
1\end{array}$ & $\begin{array}{l}6 \\
51 \\
10 \\
1\end{array}$ & $\begin{array}{l}6 \\
51 \\
10 \\
1\end{array}$ \\
\hline Total & 54 & 55 & 55 & 55 & 68 & 68 & 68 & 68 \\
\hline
\end{tabular}

GCS stands for sensor at the geometric centre of the compartment.

shaded areas. Fig. 1 shows the position of temperature probes $\# 22$ and $\# 27$ as well as the position of probe placed at the geometric centre.

\subsubsection{Calibration of temperature probes}

Each temperature sensor was calibrated before being placed on its point of measurement. The procedure of calibration consisted in determining the parameter $\alpha$ which is the temperature coefficient resistance (TCR), calculated from the resistance measured at two reference temperatures (see Eq. (1)).

$R_{\mathrm{at}}=R_{\mathrm{r}}\left[1+\alpha\left(T_{\mathrm{at}}-T_{\mathrm{r}}\right)\right] \Rightarrow \alpha=\frac{R_{\mathrm{at}}-R_{\mathrm{r}}}{R_{\mathrm{r}}\left(T_{\mathrm{at}}-T_{\mathrm{r}}\right)}$

where $R_{\mathrm{at}}$ and $R_{\mathrm{r}}$ are the resistances to both ambient ( $T_{\mathrm{at}}$ ) and reference $\left(T_{\mathrm{r}}\right)$ temperatures, respectively.

In order to determine these resistance values at two different temperatures, a mixture of ice and water was prepared. The mixture was situated over a magnetic agitator in order to obtain a low vortex movement. The RTD sensor was adjusted to the bulb of a $\mathbf{H g}$-thermometer by

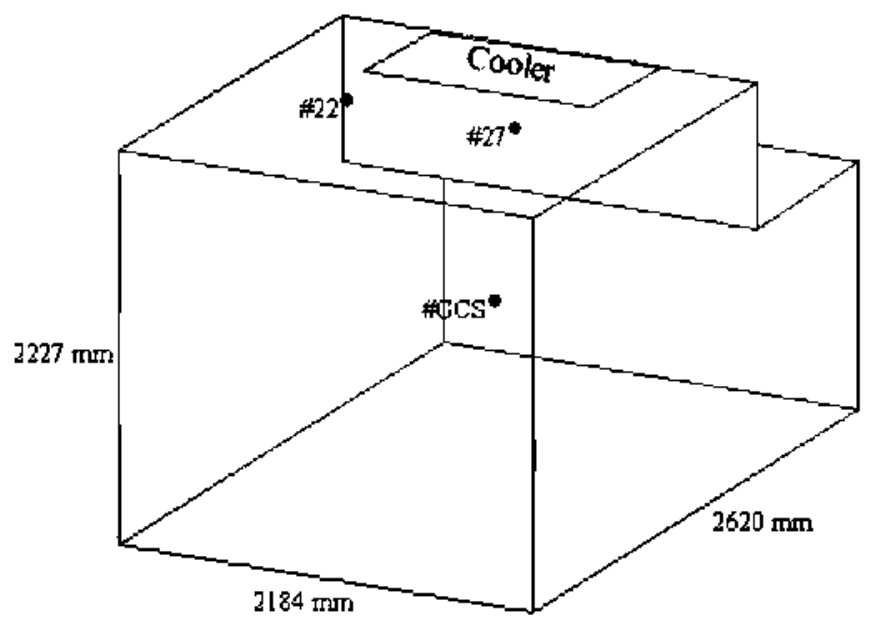

Fig. 1. Scheme of the compartment. Temperature probes $\# 22$ and $\# 27$ as well as that of the geometric centre (GCS) are marked as black dots. means of a bridle. When the temperature of melting ice was $0^{\circ} \mathrm{C}$, the temperature and the resistance were measured by the Pt 100 sensor which was connected to a digital multimeter. After that, the melting ice was substituted by water to room temperature. The thermometer-Pt 100 couple was placed into the water, and when the water temperature was made stable because of the vortex movement, temperature and resistance were again measured. The experimental TCR value for each sensor was included in the software code devoted to measure temperature data.

\subsubsection{Measurement procedure}

Temperature sensors were connected to four 40-channel differential multiplexer modules, which were plugged into slots of two data logging systems (Digital Multimeter model 2701 DMM, Integra Series, Keithley Instrument Inc., USA).

Data logger systems were connected to a local area network (LAN) using a hub, and thus, temperature data were acquired by a personal computer by means of devoted proprietary software developed using TestPoint v5. The software allows, in real-time, to display temperature data on the PC screen, saving all registered data in ASCII format.

\subsection{Experiments}

A factorial experimental design was carried out according to the state of cargo of the container (empty or full), the set point temperature $\left(0^{\circ} \mathrm{C}\right.$ and $\left.6^{\circ} \mathrm{C}\right)$ and the performance modes of the refrigeration equipment (modulated and off/ on control).

Eight different setups were tested for a three to four day period, 28 experimental dates in total. Three pallets of cargo $(2160 \mathrm{~kg})$ were used under local conditions leading to a $720 \mathrm{~kg} / \mathrm{m}^{3}$ stowed load.

\subsection{Data analysis}

Linear spatial interpolation using devoted Matlab code has been used to make 3D representations of temperature 
inside the container. Also an algorithm has been developed in order to isolate defrosting cycles from normal cooling functioning.

For statistical purposes, several analysis of variance (ANOVA) are used selecting a $48 \mathrm{~h}$ period for each experiment corresponding to a complete set of measurements during 2 days, that is to say 2152 measurements for each temperature probe (54 compared) and for each experiment (eight in total). From each, 2152 measurements per probe and experiment were made. The number of data corresponding to defrosting cycles for each experiment depends on the number of defrost firings, since defrosting is preset periodically but it only works under the presence of ice at the evaporator. Thus for comparison of defrosting and non defrosting cycles, defrost firings had to be identified and comparable sets of data (during and after defrosting) were generated. Defrosting data are not used for the analysis of the cooling system itself.

A first ANOVA compares the external temperature conditions between experiments, together with the analysis of the solar effect. Due to the significant variation of external conditions, further ANOVA analysis make use of a normalized temperature difference $\left(\Delta T_{\mathrm{n}_{i, j}}\right)$, which is computed with respect to the set point and to the outside temperatures (Eq. (2)). This value gives a normalized measure with respect to the varying ambient conditions of the experiments in order to judge the difference between the 2 cooling modes (modulated cooling, on/off control) for the four conditions (empty, loaded, $0{ }^{\circ} \mathrm{C}$ and $6{ }^{\circ} \mathrm{C}$ ).

$\Delta T_{\mathrm{n}_{i, j}}=\frac{\overline{T_{i, j}}-T_{s_{i}}}{\overline{T_{\mathrm{a}_{i}}}-T_{s_{j}}} \quad\left(\right.$ with $\left.-1<\Delta T_{\mathrm{n}_{i, j}}<1\right)$

where $\Delta T_{\mathrm{n}_{i, j}}$ stands for the normalized temperature difference for experiment $i$ and probe $j$ (with $j$ varying from 1 to 54 probes plus GCS), $\overline{T_{i, j}}$ is the average temperature value $\left({ }^{\circ} \mathrm{C}\right.$ ) of probe $j$ for experiment $i$ (two complete days period, 2152 data), $T_{s_{i}}$ is the temperature set point value $\left({ }^{\circ} \mathrm{C}\right)$ at experiment $i$, and $\overline{T_{\mathrm{a}}}$ refers to the average ambient temperature $\left({ }^{\circ} \mathrm{C}\right.$ ) in experiment $i$ (two complete days period, 2152 data). The average normalized temperature difference for all probes in experiment $i$ will be denoted as $\overline{\Delta T_{\mathrm{n}_{i}}}$.

Further ANOVAs on the normalized temperature values are computed for evaluating the effect of defrosting on average indoor temperature ( 54 probes), and on strategic probes $(22,27$ and GCS, see Fig. 1). In this case, selected pools of data have been used as mentioned before
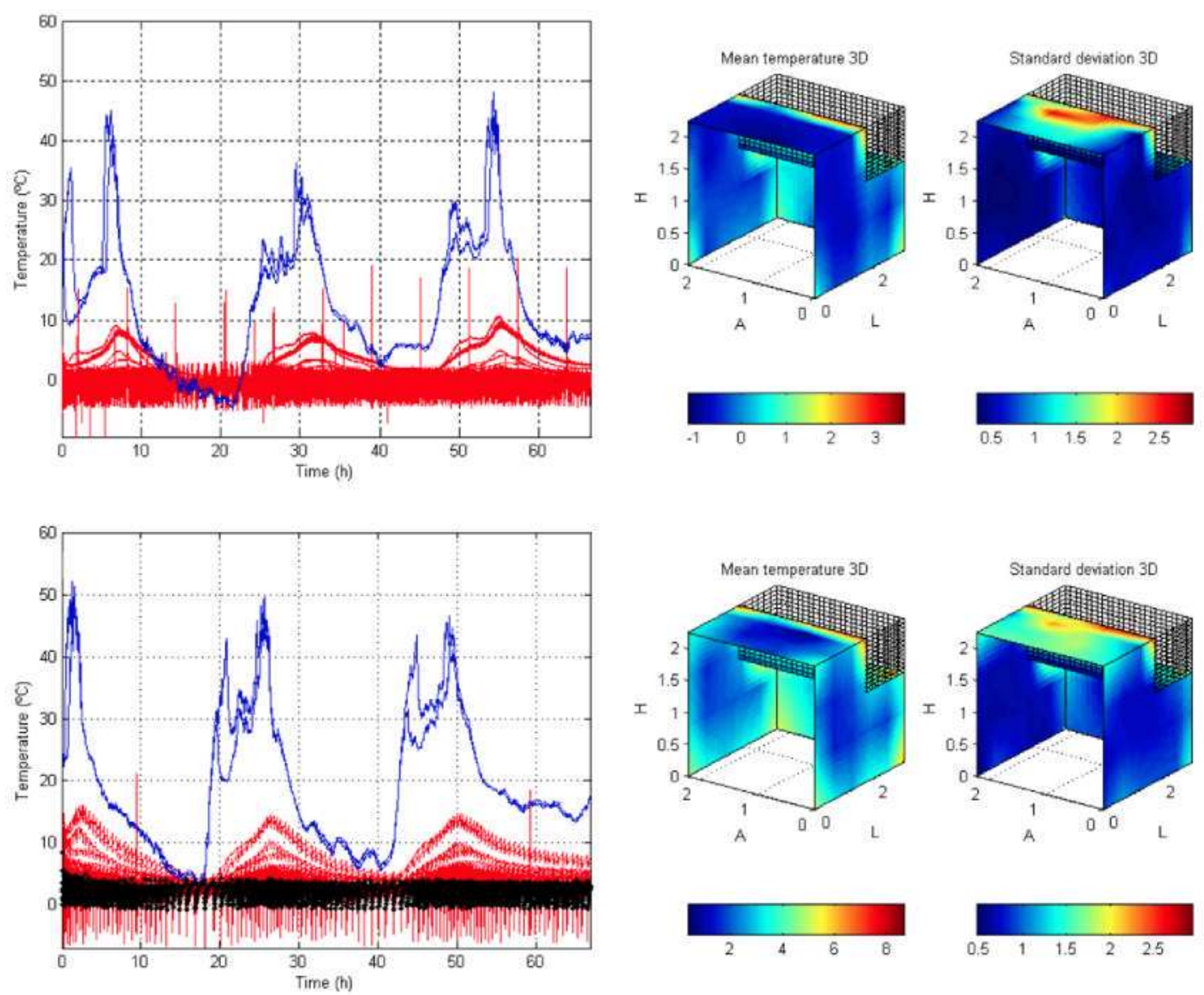

Fig. 2. Above. Temperature dynamics and 3D view of statistical parameters charts on modulated mode. Below. Temperature dynamics and 3D view of statistical parameters charts on off/on control mode. Empty container. Set point $0^{\circ} \mathrm{C}$. Blue lines refer to ambient temperature, red lines to indoor temperature and black line to the evolution of the geometric centre. 
and thus the calculation of the normalized temperature difference is performed as indicated in Eq. (3). In this case, $\overline{\Delta T_{\mathrm{n}_{i},}}$ refers to an averaging process with regard to time, this way the dispersion of data during defrost periods can be addressed.

$\Delta T_{\mathrm{n}_{i, j, t}}=\frac{T_{i, j, t}-T_{\mathrm{s}_{i}}}{\overline{T_{\mathrm{a}_{i}}}-T_{s_{i}}} \quad\left(\right.$ with $\left.-1<\Delta T_{\mathrm{n}_{i, j, t}}<1\right)$

Finally, a 3D plot of indoor temperature variance with regard to outdoor temperature variance is performed in order to represent the indoor temperature variability corrected with regard to changes in ambient experimental conditions (see Eq. (4)). The complete set of data excluding the defrosting cycles are included for each experiment.

$V_{\mathrm{n}_{i, j}}=\frac{V_{\mathrm{c}_{i, j}}}{V_{\mathrm{a}_{i}}} \quad\left(\right.$ with $\left.0<V_{\mathrm{n}_{i, j}}<1\right)$

where $V_{\mathrm{n}_{i, j}}$ is the normalized indoor variance for experiment $i$ and probe $j, V_{\mathrm{c}_{i, j}}$ is the indoor temperature variance for experiment $i$ and probe $j$, and $V_{\mathrm{a}_{i}}$ is the ambient variance for experiment $i$ according to the external sensor situated on the sunny side.

\section{Results and discussion}

In this paragraph, whole dynamic behaviour together with the specific statistical analysis of the experimental factors are presented.

\subsection{Empty container}

Figs. 2 and 3 show global temperature behaviour for the experimental set-ups that made use of the empty container. Blue and red lines refer to ambient and indoor data respectively, while the black line corresponds to the geometric centre of the compartment with the empty container. As expected, relevant temperature gradients are found during each three day period. Summary of $3 \mathrm{D}$ views are provided corresponding to both the mean and the standard deviations of temperature data during each experiment.

Fig. 2 shows that indoor temperature data separate from the temperature set point for off/on control mode compared to the modulated one. Several temperature peaks are advisable for the modulated mode which corresponds to defrosting phases, that is heat generation by the cooler. Even for modulated mode, several indoor temperature
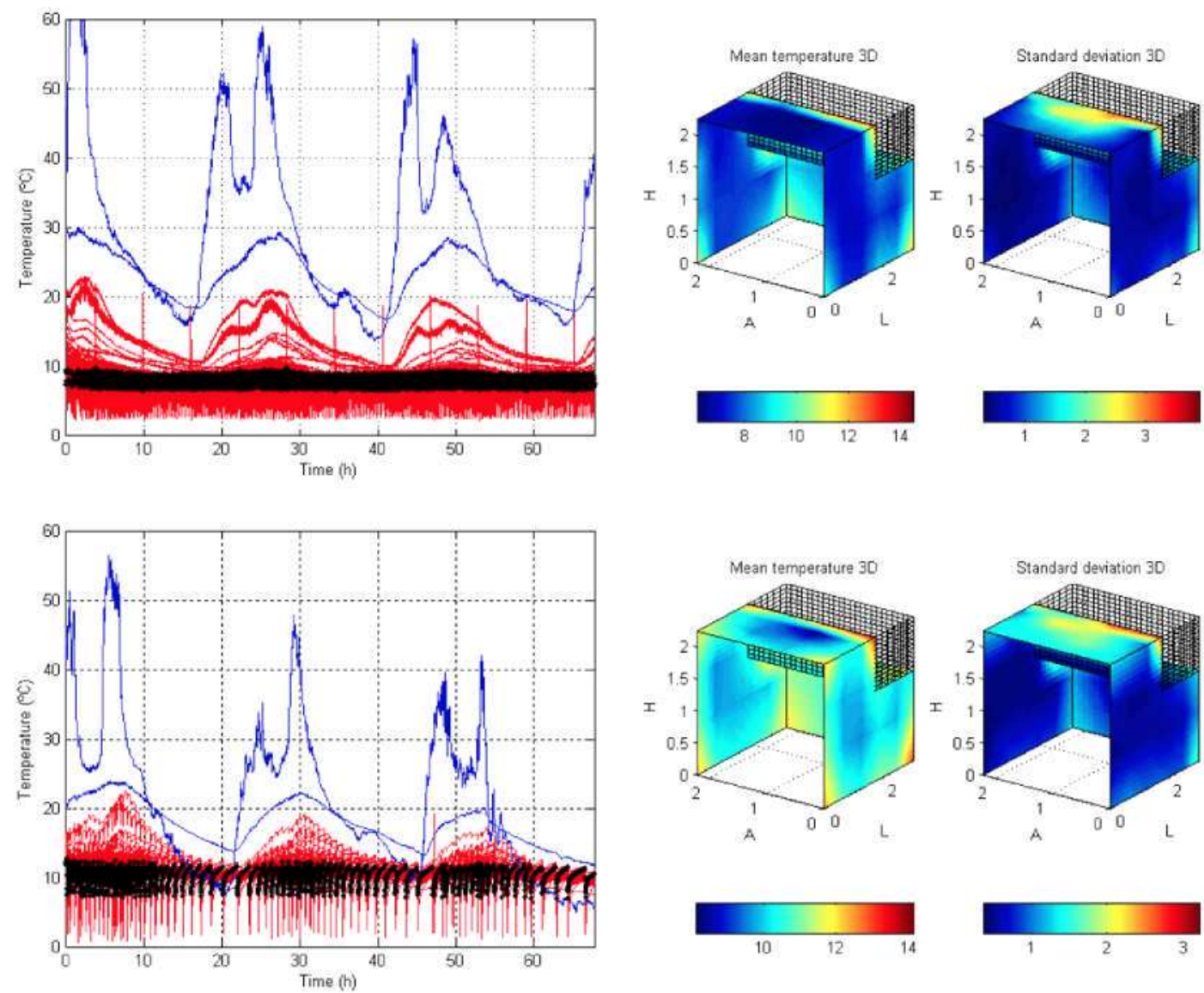

Fig. 3. Above. Temperature dynamics and 3D view of statistical parameters charts on modulated mode. Below. Temperature dynamics and 3D view of statistical parameters charts on off/on control mode. Empty container. Set point $6^{\circ} \mathrm{C}$. Blue lines refer to ambient temperature, red lines to indoor temperature and black line to the evolution of the geometric centre. 
probes clearly separate from the set point which corresponds to the ceiling. For this experiment, both ambient sensors were situated on the ceiling of the container and, thus, in sunny conditions. When the cooler worked in off/on control mode, several differences are found compared to modulated mode. Only two peaks corresponding to defrosting cycles are found as automatic defrost was set. Besides, the frequency of thermal cycles derived from the on-off switching of the cooler decreased during the night, as a consequence of the lower outer ambient temperature. $3 \mathrm{D}$ charts show that significant indoor temperature differences exist at several locations in the container, and that such variations are enhanced by the function mode of the cooler (modulated and off/on control). In both cases the highest temperature variability corresponds to the roof nearby the position of the cooler.

Fig. 3 shows the results of experiments carried out for $6{ }^{\circ} \mathrm{C}$ set point. A similar dynamic behaviour as compared to Fig. $1\left(0^{\circ} \mathrm{C}\right)$ is found. However, in this case a remarkable separation of actual temperature from the selected set point was always found even for the geometric centre of the container. This phenomenon occurred in both types of cooler performance. The mean temperature observed was $8^{\circ} \mathrm{C}$ in both modulated and off/on control modes, that is $2{ }^{\circ} \mathrm{C}$ above the set point. $3 \mathrm{D}$ charts remark that the average temperature, under modulated mode, was rather homogeneous across the container while temperature variability was enhanced on off/on control mode. It can be observed that the lowest mean temperatures were registered by the sensors situated in the ceiling opposite the air stream. Mean temperatures of sensors placed on the walls were also lower than mean temperatures from corners. The standard deviations charts show that the highest temperature variations were registered in the ceiling of the compartment, due to the solar effects. In the case of modulated performance, the solar effects were attenuated by the air stream.

\subsection{Loaded container}

Figs. 4 and 5 present the experimental results corresponding to a loaded container. In these cases, three pallets were used, each one containing up to $1445-1$ bottles of water $\left(720 \mathrm{~kg} / \mathrm{m}^{3}\right)$. The results show that ambient temperature was lower than for previous experiments, since these tests were carried out in October and the beginning of November, while previous tests took place between March and May. As before, the temperature corresponding to the
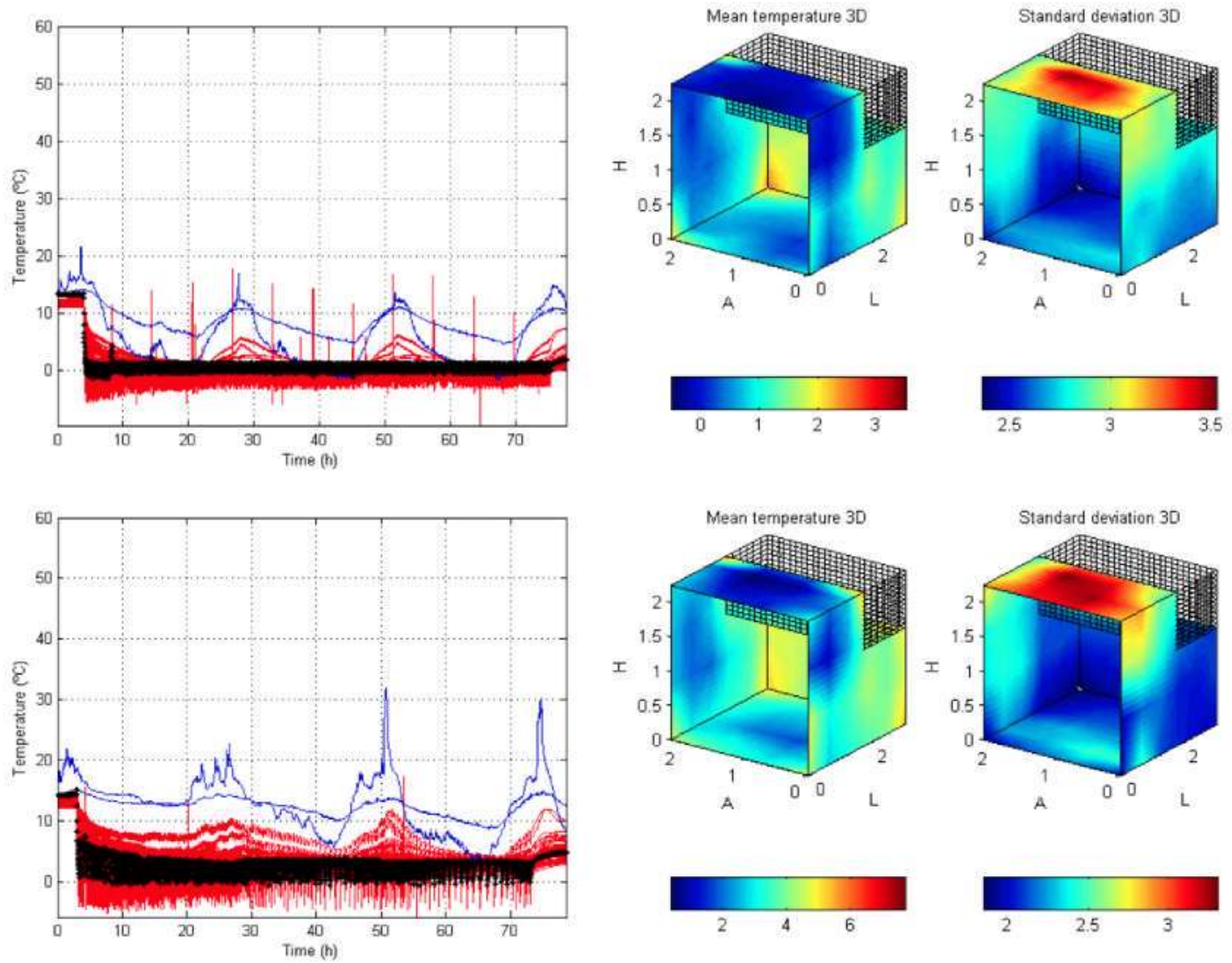

Fig. 4. Above. Temperature dynamics and 3D view of statistical parameters charts on modulated mode. Below. Temperature dynamics and 3D view of statistical parameters charts on off/on control mode. Loaded container. Set point $0^{\circ} \mathrm{C}$. Blue lines refer to ambient temperature, red lines to indoor temperature and black line to the evolution of the geometric centre. 

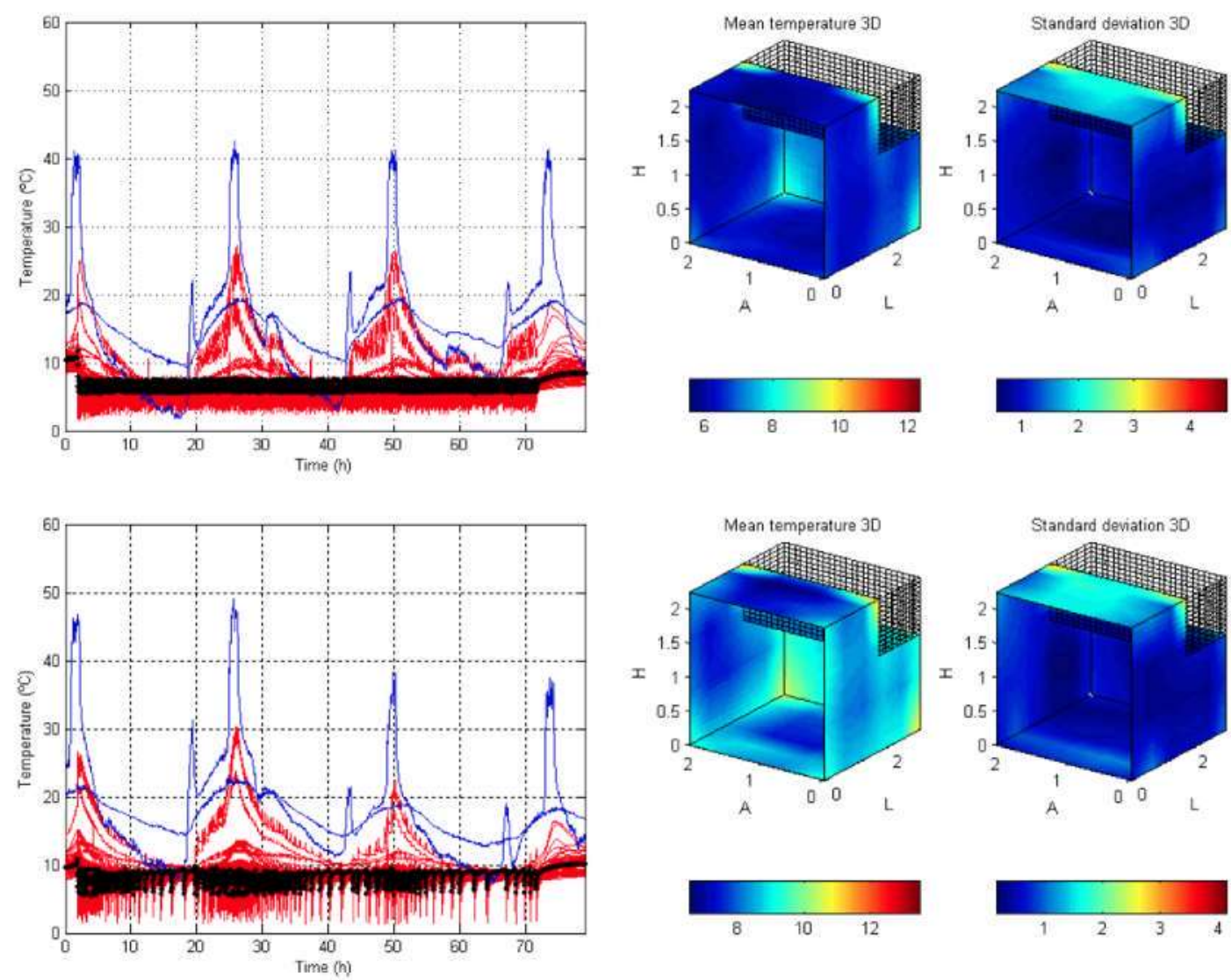

Fig. 5. Above. Temperature dynamics and 3D view of statistical parameters charts on modulated mode. Below. Temperature dynamics and 3D view of statistical parameters charts on off/on control mode. Loaded container. Set point $6{ }^{\circ} \mathrm{C}$. Blue lines refer to ambient temperature, red lines to indoor temperature and black line to the evolution of the geometric centre.

geometric centre was nearer to the set point under modulated compared to off/on control mode. 3D plots show that the highest temperatures were registered below the cooler. This factor could be due to the cargo, which affected air flow pattern even though air channels were available according to industry recommendations. The 3D standard deviation plot show that the higher temperature variations were observed on the top of the compartment, due to the influence of the solar effects and defrosting. Fig. 5 shows the experimental results corresponding to a loaded container at $6{ }^{\circ} \mathrm{C}$ set point. In this case, defrosting peaks are again observed under modulated mode performance. It is worth noting that the average temperature registered by the sensor located in the geometric centre was always higher than the set point. In addition, under off/on control cooling, changes in the frequency of switching were found, being higher during the day than at night. For off/on control experiment, the outer temperatures registered during the last two days were on average lower than temperatures in the first two and so the frequency of switching was lower during the last two days than for the previous ones. Average $3 \mathrm{D}$ charts show that spatial temperature variations are relevant in both performance modes. Spatial variations were enhanced under off/on control mode.

\section{Analysis of variance}

As indicated, several analysis of variance have been carried out in order to determine the evolution of ambient data together with the effect of experimental factors such as: load level, defrosting and cooler performance modes on the indoor temperature of the container.

\subsection{Comparison of ambient data}

Both the seasonal temperature evolution together with the solar effects are evaluated in this paragraph. The temperature data registered by two ambient probes are used: one situated on the roof (sun exposure) while the other is placed under the container (shade). Only the data from experiments $3-8$ are used since for the 2 first experiments, no shade data are available. Table 2 and Fig. 6 summarize the results for ANOVA which indicate a strong variation of ambient conditions between experiments. Experiments \#3 and \#4 were carried out in March. In these experiments, temperature sensor situated on the roof of the container registered higher temperatures than the probe under the container, due to the influence of the sun. Temperature data obtained in experiments $\# 7$ and $\# 8$ show that the 
Table 2

Statistic parameters of the analysis of ambient temperature

\begin{tabular}{lccccc}
\hline & Sum of square SS & Degrees of freedom DF & Mear square MS & Fisher value $F$ & Probability level $P$ level \\
\hline Exp & $\mathbf{1 , 4 0 9 , 3 8 5}$ & 7 & $\mathbf{2 0 1 , 3 4 1}$ & $\mathbf{4 7 9 4 . 7}$ & $*$ \\
Solar effect & $\mathbf{1 6 4 , 8 1 0}$ & $\mathbf{1}$ & $\mathbf{1 6 4 , 8 1 0}$ & $\mathbf{3 9 2 4 . 8}$ & $* *$ \\
Exp * solar effect & $\mathbf{4 6 5 , 0 2 0}$ & $\mathbf{7}$ & $\mathbf{6 6 , 4 3 1}$ & $\mathbf{1 5 8 2 . 0}$ & $*$ \\
Error & $1.446,541$ & 34,448 & 42 & & $*$
\end{tabular}

Data set: 25.848 measurements corresponding to 6 experiments $* 2$ temperature probes * 1076 measurements per probe.

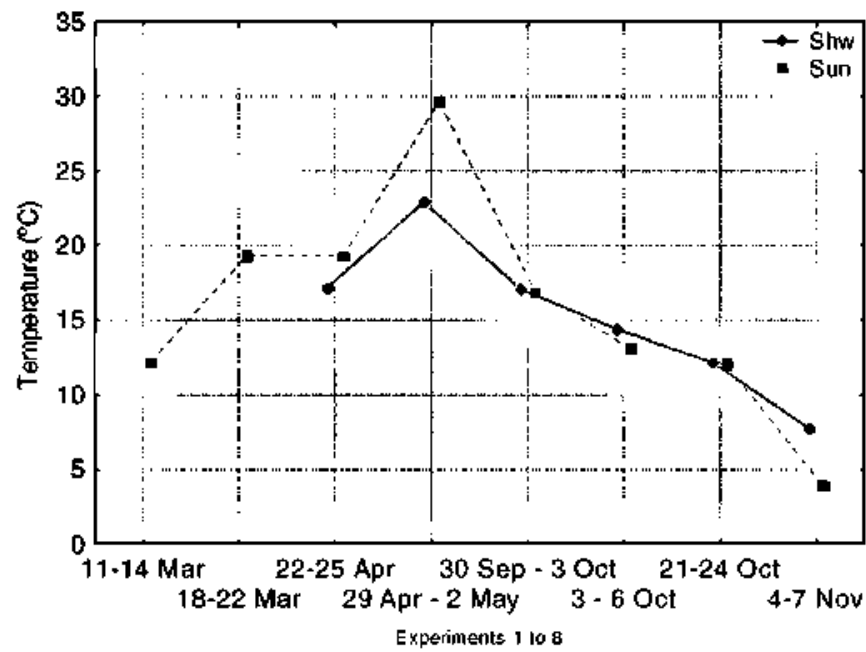

Fig. 6. Analysis of ambient conditions.

influence of the solar effects decreased highly when corresponding to winter conditions. For experiment \#7, solar and shade temperatures were very similar, while for experiment \#8, the solar effects were even lower than the temperature registered by the probe in shade. Probably, the heat stored in the floor influenced such behaviour. Both experiments were carried out at the end of October and in the first week of November. The strong influence of ambient led to the need of defining a normalized parameter for indoor characterization, which has been described in paragraph 2.

\subsection{Analysis of the cooler performance}

For this analysis, data recorded during defrosting cycles have been disregarded. Three factors have been studied in this analysis: the cooler performance (modulated or off/ on control), the set point $\left(0^{\circ} \mathrm{C}\right.$ or $\left.6^{\circ} \mathrm{C}\right)$ and the level of cargo $\left(0 \mathrm{~kg} / \mathrm{m}^{2}\right.$ and $\left.720 \mathrm{~kg} / \mathrm{m}^{2}\right)$. Table 3 shows the results of ANOVA for the normalized temperature difference
Table 3

ANOVA of the normalized temperature difference $\left(\Delta T_{\mathbf{n}_{i, i}}\right)$ for different cooling control strategies (modulated and on-off control), set point ( 0 and $\left.6{ }^{\circ} \mathrm{C}\right)$ and cargo levels $\left(0\right.$ and $\left.720 \mathrm{~kg} / \mathrm{m}^{3}\right)$

\begin{tabular}{llrlrl}
\hline & SS & DF & \multicolumn{1}{l}{ MS } & \multicolumn{1}{l}{$F$} & $P$ \\
\hline M/on-off & $\mathbf{4 . 8 6 7}$ & $\mathbf{1}$ & $\mathbf{4 . 8 6 7}$ & $\mathbf{4 7 0 . 0 0 7}$ & $* *$ \\
SP & 0.945 & 1 & 0.945 & 91.225 & $* *$ \\
L/E & 0.156 & 1 & 0.156 & 15.103 & $* *$ \\
M/on-off * SP & 0.052 & 1 & 0.052 & 5.047 & $*$ \\
M/on-off * L/E & 0.009 & 1 & 0.009 & 0.881 & NS \\
SP * L/E & $\mathbf{0 . 5 6 0}$ & 1 & $\mathbf{0 . 5 6 0}$ & $\mathbf{5 4 . 1 1 1}$ & $* *$ \\
M/on-off * SP * L/E & 0.121 & 1 & 0.121 & 11.711 & $* *$ \\
Error & 4.391 & 424 & 0.010 & & \\
\hline
\end{tabular}

Data set: 432 measurements corresponding to 2 set points $* 2$ cooling modes $(\mathrm{M} / \mathrm{on}-\mathrm{oft}) * 2$ cargo levels $(\mathrm{L} / \mathrm{E}) * 54$ probes.

( $\Delta T_{\mathrm{n}_{2,},}$ ). The highest effect is found for the type of cooling: on-off vs. modulated ( $F=470.007)$, and the interaction between set point and cargo ( $\mathrm{SP} * \mathrm{~L} / \mathrm{E}, F=54.111$ ).

When the container worked in modulated mode, $\Delta T_{\mathrm{n}_{i, s}}$ was very close to 0 , that is to say the absolute temperature was close to the set point for $0{ }^{\circ} \mathrm{C}$ set point and empty container $\Delta T_{\mathrm{n}_{i, j}}$ was -0.025 , that is to say average temperature was below the set point (see Table 4). For the empty container at $6^{\circ} \mathrm{C}$ set point, the cooling system failed to achieve the target, even in modulated mode being always above the set point. The worst situation was always found for on-off control, where $\Delta T_{\mathrm{n}_{j,},}$ was always above 0.15 , which refers to temperature miss matches compared to the set point above $10 \%$ of ambient temperature. These values even reached 0.37 for $6^{\circ} \mathrm{C}$ set point and empty container.

\subsection{Average thermal behaviour with and without defrosting}

The thermal effect of defrosting is studied in this analysis using the normalized temperature difference $\Delta T_{\mathrm{n}_{i, j}}$ from 54 temperature probes. Data subsets have been selected for each experiment corresponding to defrosting cycles plus control measurements. The identification of defrosting

Table 4

Effect of the cooler performance on the average normalized temperature difference $\left(\Delta T_{\mathrm{b}_{2, j}}\right.$ ) for both empty and loaded container at $0{ }^{\circ} \mathrm{C}$ and $6{ }^{\circ} \mathrm{C}$ set points

\begin{tabular}{llrrr}
\hline & Set point $0^{\circ} \mathrm{C}$ & & \multicolumn{2}{c}{ Set point $6^{\circ} \mathrm{C}$} \\
\cline { 2 - 4 } & Loaded & \multicolumn{1}{c}{ Empty } & \multicolumn{1}{c}{ Loaded } \\
\hline Modulated & $-0.002 \pm 0.014$ & $-0.012 \pm 0.014$ & $0.03 \pm 0.014$ & Enpty \\
On-off & $0.212 \pm 0.014$ & $0.154 \pm 0.014$ & $0.222 \pm 0.014$ & $0.098 \pm 0.014$ \\
\hline
\end{tabular}


Table 5

ANOVA of the normalized temperature difference $\left(\Delta T_{\mathrm{D}_{2,}}\right)$ for a subset of data gathering. defrosting cycles (defrosting or control), cooling control strategies (modulated and on-off control), set point $\left(0\right.$ and $\left.6^{\circ} \mathrm{C}\right)$ and cargo levels $\left(0\right.$ and $\left.720 \mathrm{~kg} / \mathrm{m}^{3}\right)$

\begin{tabular}{lrrlrl}
\hline & SS & DF & \multicolumn{1}{l}{ MS } & \multicolumn{1}{l}{$F$} & $P$ \\
\hline SP & $\mathbf{1 . 8 7 9}$ & $\mathbf{1}$ & $\mathbf{1 . 8 7 9}$ & $\mathbf{8 2 . 5 0 4}$ & $* *$ \\
Defrost & $\mathbf{1 . 1 0 5}$ & $\mathbf{1}$ & $\mathbf{1 . 1 0 5}$ & $\mathbf{4 8 . 5 1 8}$ & $* *$ \\
M/on-off & $\mathbf{8 . 1 7 4}$ & $\mathbf{1}$ & $\mathbf{8 . 1 7 4}$ & $\mathbf{3 5 8 . 8 1 7}$ & $* *$ \\
L/E & $\mathbf{0 . 1 4 6}$ & 1 & 0.146 & 6.430 & $*$ \\
SP * defrost & 0.064 & 1 & 0.064 & 2.813 & NS \\
SP * M/on-off & 0.448 & 1 & 0.448 & 19.676 & $* *$ \\
Defrost * M/on-off & 0.003 & 1 & 0.003 & 0.146 & NS \\
SP * L/E & $\mathbf{1 . 0 8 5}$ & 1 & $\mathbf{1 . 0 8 5}$ & $\mathbf{4 7 . 6 1 9}$ & $* *$ \\
Defrost * L/E & 0.047 & 1 & 0.047 & 2.082 & NS \\
M/on-off * L/E & 0.163 & 1 & 0.163 & 7.159 & $*$ \\
SP * defrost * M/on-off & 0.028 & 1 & 0.028 & 1.231 & NS \\
SP* defrost *L/E & 0.048 & 1 & 0.048 & 2.114 & NS \\
SP* M/on-off * L/E & 0.147 & 1 & 0.147 & 6.447 & $*$ \\
Defrost * M/on-off * L/E & 0.012 & 1 & 0.012 & 0.521 & NS \\
SP * defrost * M/on-off * L/E & 0.009 & 1 & 0.009 & 0.377 & NS \\
Error & 19.318 & 848 & 0.023 & & \\
\hline
\end{tabular}

Data set: 864 measurements corresponding to 8 experiments $* 2$ defrosting modalities $($ on - off $) * 54$ probes.
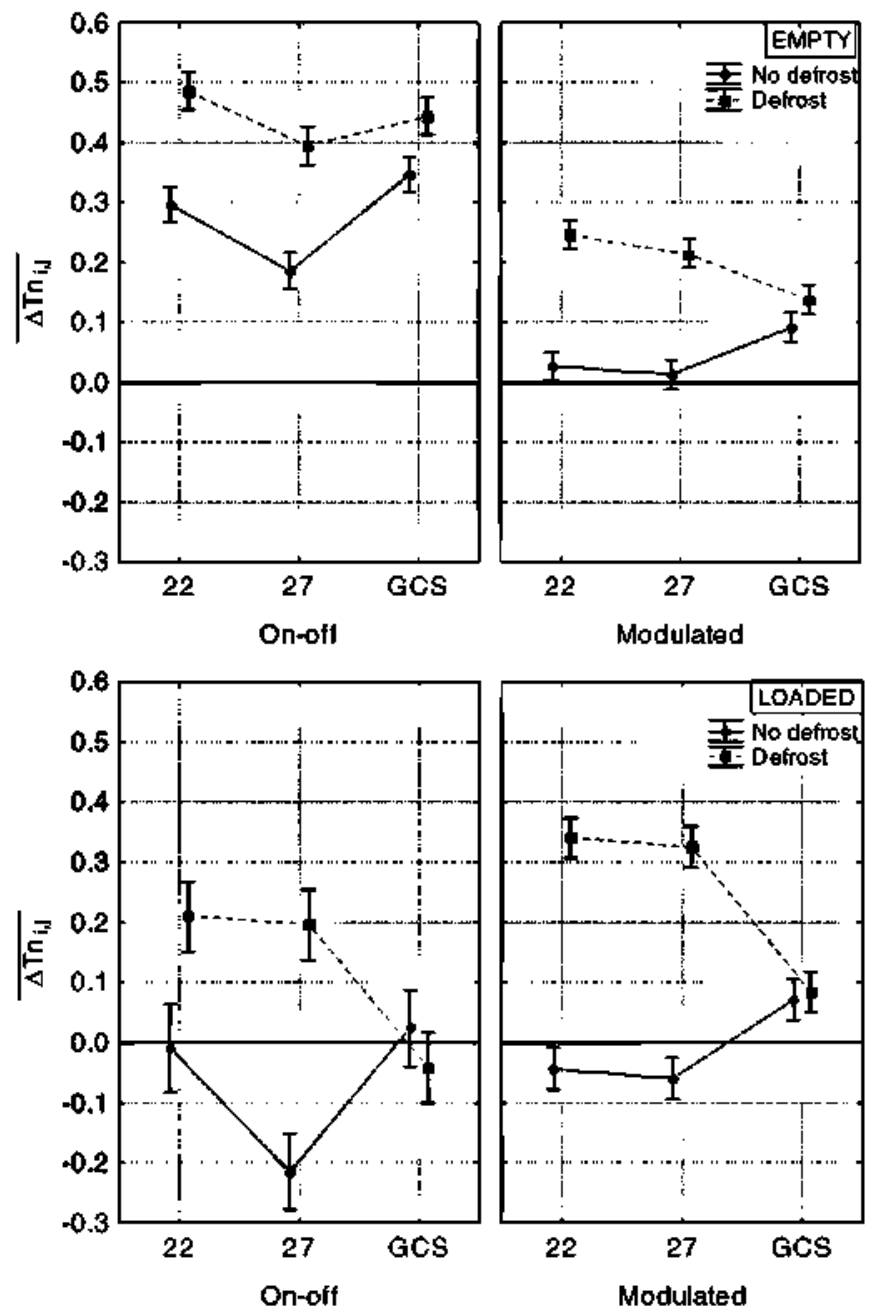

Fig. 7. Average normalized temperature difference $\left(\overline{\Delta T}_{n_{i, j}}\right)$ considering set point $6{ }^{\circ} \mathrm{C}$ for probes $\# 22$. $\# 27$ and GCS, with varying experimental factors. cycles is not straight-forward since it may occur that the defrosting system is not fired at the expected time schedule due to the lack of ice in the evaporator, and thus devoted algorithms have been developed to identify defrosting activity.

Numerous defrosting cycles are always identified for modulated functioning of the cooling system (10-12), while very limited cases of defrosting are found for on-off control $(1-3)$, see temporal plots in Figs. 2-5.

As control samples (non defrosting cycles), equivalent number of data to those of defrosting cycles have been selected for each experiment corresponding to half an hour late for each defrost end. In total, 16 sets of data: 8 defrosting and 8 non-defrosting were evaluated for defrosting.

The results for ANOVA shown in Table 5 indicate that most relevant factors are the type of cooling: modulated vs. on-off $(F=358.82)$, set point $(F=82.5)$, defrosting cycle $(F=48.52)$ and the interaction between set point and cargo $(\mathrm{SP} * \mathrm{~L} / \mathrm{E}, F=47.62)$.

A more detailed study was then performed taking into account three specific temperature probes: two situated opposite the air stream from the cooler ( $\# 22$ and $\# 27$ ) and another one corresponding to the geometrical centre sensor (GCS). The effect of the defrosting on such locations can be observed in Fig. 7. ANOVA results on the average

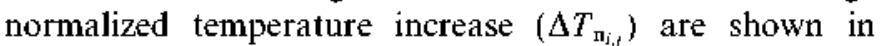
Table 6. From Fig. 7 (set point $6^{\circ} \mathrm{C}$ ) and Table 5 (all data), a major conclusion is that the effect of defrosting is very high on probes $\# 22$ and $\# 27$ specially for modulated cooling. The effect of defrosting is not as noticeable at the geometric centre especially for a loaded container. Note that in these cases the number of defrosting cycles was also very high.

Table 6

ANOVA of the normalized temperature difference $\left(\Delta T_{\mathrm{b}_{i,}}\right)$ for three strategic temperature probes (\#22, \#27 and GCS) including defrosting cycles (defrosting or control), cooling control strategies (modulated and on-off control), set point $\left(0\right.$ and $\left.6{ }^{\circ} \mathrm{C}\right)$ and cargo levels $\left(0\right.$ and $\left.720 \mathrm{~kg} / \mathrm{m}^{3}\right)$

\begin{tabular}{lrrrrl}
\hline & \multicolumn{1}{c}{ SS } & DF & \multicolumn{1}{c}{ MS } & \multicolumn{1}{c}{$F$} & $P$ \\
\hline Probe & 1.1321 & 2 & 0.56 & 16.391 & $* * *$ \\
Defrost & $\mathbf{2 2 . 2 4 5 0}$ & $\mathbf{1}$ & $\mathbf{2 2 . 2 4}$ & $\mathbf{6 4 4 . 1 4}$ & $* *$ \\
M/on-off & 1.0204 & 1 & 1.02 & 29.54 & $* *$ \\
L/E & $\mathbf{3 . 1 3 9 1}$ & $\mathbf{1}$ & $\mathbf{3 . 1 4}$ & $\mathbf{9 0 . 8 9}$ & $* *$ \\
Probe * defrost & $\mathbf{1 0 . 8 8 5 0}$ & $\mathbf{2}$ & $\mathbf{5 . 4 4}$ & $\mathbf{1 5 7 . 5 9}$ & $* *$ \\
Probe * M/on-off & 0.8390 & 2 & $\mathbf{0 . 4 2}$ & 12.14 & $* *$ \\
Defrost * M/on-off & 2.4668 & $\mathbf{1}$ & $\mathbf{2 . 4 7}$ & $\mathbf{7 1 . 4 3}$ & $* *$ \\
Probe * L/E & 0.1845 & 2 & 0.09 & 2.67 & NS \\
Defrost * L/E & 1.5115 & 1 & 1.51 & 43.77 & $* *$ \\
M/on-off * L/E & 1.0662 & 1 & 1.07 & 30.87 & $* *$ \\
Probe * defrost * M/on-off & 1.0031 & 2 & 0.50 & 14.52 & $* *$ \\
Probe* defrost * L/E & 2.5337 & 2 & 1.27 & 36.68 & $* *$ \\
Probe * M/on-off * L/E & 0.2481 & 2 & 0.12 & 3.59 & $*$ \\
Defrost * M/on-off * L/E & 0.0091 & 1 & 0.009 & 0.26 & NS \\
All & 0.2920 & 2 & 0.16 & 4.23 & $*$ \\
Error & 246.9902 & 7152 & 0.034 & & \\
\hline
\end{tabular}

Data set: 7176 measurements corresponding to 7 experiment $* 3$ probes $* 2$ defrosting status (on-oft) $* 166$ measurements per defrosting status and probe on average. 


\subsection{Representation of $3 D$ normalized indoor variance}

In previous paragraphs, the effect of experimental factors such as cooling mode, set points, level of cargo and defrosting, have been studied. In this paragraph, a 3D study of the normalized indoor variance $\left(V_{\mathrm{n}_{i, j}}\right)$ is presented without considering the defrosting cycles.

Table 7 shows the normalized indoor variance for the sensor situated at the geometric centre. It can be appreciated that $V_{\mathrm{n}_{i, j}}$ is higher for on-off control (1-6\% of ambient variance) compared to modulated cooling $(0-2 \%)$. It is necessary to remark that for the first experiment, no data are available since there were no sensors at the geometrical centre. The highest indoor variance is found for loaded containers under on-off cooling control, while the lowest is always found for modulated cooling.

Fig. 8 shows the 3D plot for the normalized indoor variance for the rest of the probes. $V_{\mathrm{n}_{i, j}}$ remains around 0.1

Table 7

Normalized temperature variance $\left(V_{\mathrm{B}_{i j}}\right)$ at the geometric centre of compartment and (average percentage of time) within industry recommendations (set point $\pm 0.5^{\circ} \mathrm{C}$ )

\begin{tabular}{llllll}
\hline & \multicolumn{2}{l}{ Set point $0^{\circ}$} & & & \multicolumn{2}{l}{ Set point $6^{\circ}$} \\
\cline { 2 - 3 } \cline { 6 - 7 } & $\mathrm{C}$ & $\mathrm{NC}$ & & $\mathrm{C}$ & $\mathrm{NC}$ \\
\hline Empty & - & 0.01 & & 0.00 & 0.03 \\
& $(-)$ & $(9.57 \%)$ & & $(0.1 \%)$ & $(0 \%)$ \\
Loaded & 0.02 & 0.06 & & 0.00 & 0.01 \\
& $(52.35 \%)$ & $(8.53 \%)$ & & $(44.37 \%)$ & $(5.76 \%)$ \\
\hline
\end{tabular}

( $10 \%$ of ambient variance). The highest variability corresponds to the ceiling. Also some areas in the floor indicate abnormal ventilation at that point and thus temperature increases.

Tanner and Amos (2003a) also observed thermal variations in their studies on containers. They found great spatial variability although the average temperature was maintained near the set point. It can be stated that the different standard deviation values were produced by the establishment of the circulating airflow patterns. Nahor et al. (2004) also observed spatial thermal differences in a cool room when it was empty and loaded.

\subsection{Analysis of the percentage of time within the industry recommended interval}

Several studies include an analysis of the percentage of time within the industrial recommended interval for several temperature sensors. Tanner and Amos (2003a) observed that their container was within this interval for approximately $58 \%$ of the delivery time. They concluded that the left side was warmer than the right one, likely because of differential defrosting.

In this study, Table 7 shows the average percentage of time that the geometric centre was within the industry tolerance of $\pm 0.5^{\circ} \mathrm{C}$. It can be observed that for modulated cooling loaded container percentages were always higher ( $52 \%$ and $44 \%$ ) than for off/on control of the empty container $(9.6 \%$ and $0 \%)$. Thermal inertia of cargo has a clear effect on the stabilization of temperature but, the use of off/ on control cooling did not enable in any case the achieve-

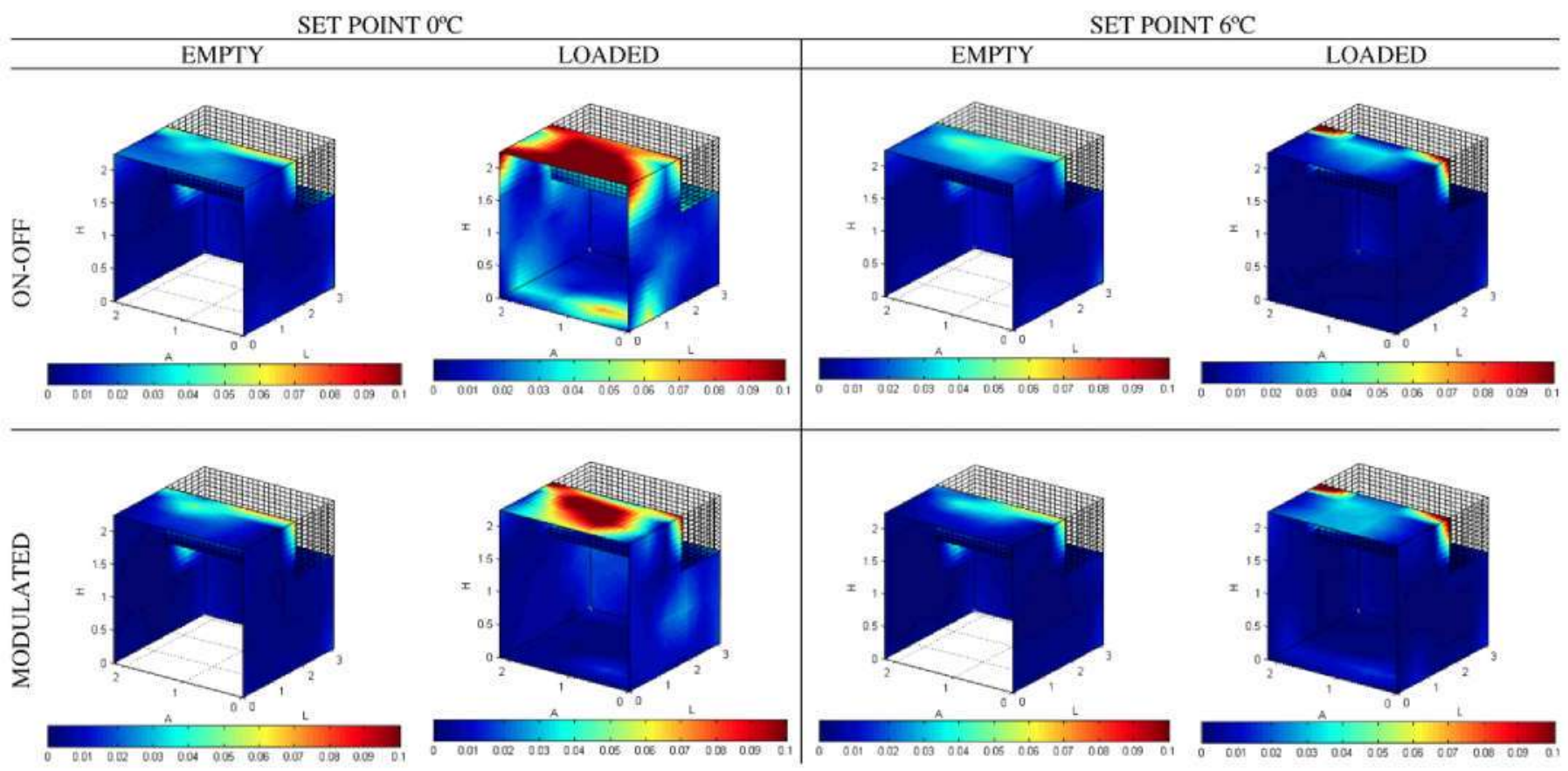

Fig. 8. 3D plot of normalized indoor variance $\left(V_{\mathrm{n}, j}\right)$. This parameter expresses the indoor temperature variability with regard to outdoor changes. Visualization range cover between 0 and $10 \%$ of outdoor variance. 
ment of industry recommendations. In these experiments, lower percentages of time within industry recommendations are found for high temperature set points.

\section{Conclusions}

The following conclusions are derived from this study:

1. Ambient temperature, particularly solar effect, has significant influence on the indoor temperature. Average sun-shade difference for outdoor temperature reaches more than $7^{\circ} \mathrm{C}$ and so, walls exposed to sun radiation show clearly differentiated thermal patterns compared to shaded ones.

2. A normalized parameter for evaluating indoor temperatures has been defined $\left(\Delta T_{\mathrm{n}_{i, j}}\right)$ as the difference between indoor temperature compared to the set point divided by the difference between the average ambient temperature of the experiment to the set point. This parameter has stayed between 0 and 0.40 for all experiments. Negative values indicate that indoor temperature stays below the set point (excessive refrigeration) while positive values refer to insufficient refrigeration.

3. The existence of short-time defrosting periods during the cooling process, generates very high local temperature increases $\left(+0.2<\overline{\Delta T_{\mathrm{n}_{i, j}}}<+0.5\right)$ which do not reach the geometric centre $\left(-0.05<\overline{\Delta T_{\mathrm{n}_{i, j}}}<+0.08\right)$ when the container is loaded $\left(720 \mathrm{~kg} / \mathrm{m}^{3}\right)$. During cooling, temperatures far below the set point are also found locally $\left(\overline{\Delta T_{n_{r, j}}}<-0.2\right)$.

4. Also a normalized indoor variance $\left(V_{\mathrm{n}_{i,}}\right)$ has been defined to evaluate maximum indoor variance compared to that of ambient for each experiment. This value has stayed between 0 and 0.16 in all cases as stated in 3D graphs.

5. As expected, modulated cooling allows best thermal homogeneity compared to off/on control mode. The geometric centre of the compartment showed $V_{\mathrm{n}_{i, j}}$ between 0 and 0.02 , for modulated cooling, while reaching up to 0.06 for on-off control. Also the ability to address the predefined set point was higher for modulated cooling $\left(\Delta T_{\mathrm{n}_{i, l},}\right.$ below 0.05) than for on-off control mode ( $\Delta T_{\mathrm{n}_{l, j}}$ always above 0.1 ).

6. Under off/on control cooling mode, the frequency of switching of the cooler is much higher at noon that at night, in spring-summer than in winter and higher for an empty container than for loaded compartments.

7. Current control strategies for off/on control refrigeration have shown to be very poor for maintaining industry recommendations: set point $\pm 0.5^{\circ} \mathrm{C}$, since the percentage of time within industry recommendation for the geometric centre of the container was always below $10 \%$. Further research for improving cooling mode strategies that enable thermal restrictions and minimal energy consumption are needed. Experimental data sets will be used for testing analytical models in future works.

\section{Acknowledgements}

This research was supported by the Spanish Ministry of Education in the framework of Sensofrigo (MCYT AGL2003-06073-CO2). It has been carried out in the Spanish Council for Scientific Research (CSIC) and the program TAGRALIA.

\section{References}

Dinçer (2003). Refrigeration systems and applications. Chichester, England: Wiley. p. 357.

European Commission. (2001). White paper: European transport policy for 2010: time to decide. COM(2001) 370 Final.

Hoang, M. L., Verboven, P.. Baelmans. M.. \& Nicolaï, B. M. (2004). Sensitivity of temperature and weight loss in the bulk of chicory roots with respect to process and product parameters. Joumal of Food Engineering, 62. 233-243.

Keesman, K. J.. Diederik. P.. \& L tıkasse. L. J. S. (2003). Optimal clinate control of a storage facility using local weather forecasts. Control Engineering Practice, 11, 505-516.

Lindqvist. R. (1998). Reefer hold distribution. Preprint Conferences. I.I.F./I.I.R.. Canbridge, UK.

Lindqvist R. (1999). Air distribution design for controlled atmosphere in refer cargo holds. 20th International Congress of Refrigeration. IIIF, I.I.R., Sydney.

Moureh, J, \& Flick. D. (2004). Airflow pattern and temperature distribution in a typical refrigerated truck configuration loaded with pallets. International Jotunal of Refrigeration, 27, 464-474.

Moureh. J., Menia. N., \& Flick, D. (2002). Numerical and experimental study of airfow in a typical refrigerated truck configuration loaded with pallets. Computers and Electronics in Agriculture, 34, 25-42.

Nahor, H. B., Hoang, M. L., Verboven, P., Baelmans, M., \& Nicolaï, B. M. (2004). CFD model of the airflow, heat and mass transfer in cool stores. International Joturnal of Refrigeration, 28, 368-380.

Scott, G., \& Richardson, P. (1997). The application of computational fluid dynamics in the food industry. Trends in Food Science \& Techology, 8 . 119-124, Review article.

Tanner, D. J.. \& Amos, N. D. (2003a). Temperature variability during shipments of fresh produce. Acta Horticultarae, 599, 193-203.

Tanner, D. J., Amos, N. D. (2003b). Modeling product quality changes as a result of temperature variability in shipping systems. Intemational Congres's of Refrigeration.

Verboven, P.. Hoang. M. L.. Baelmans. M.. \& Nicolaï, B. M. (2004). Airflow through beds of apples and chicory roots. Biosystems Engineering, 88(1), 117-125.

Verboven, P., Hoang, M. L., \& Nicolaï, B. (2003). Modeling turbulent air flow in cool rooms for horticultural products. Acta Horticulturae, 599, 435-441.

Wang, L., \& Sun, D. (2003). Recent developments in numerical modeling of heating and cooling processes in the food industry. Trends in Food Science \& Technologv, 14. 408-423. Review.

Xia, B.. \& Sun. D. (2002). Applications of computational fluid dynanics (CFD) in the food industry: a review. Computers and electronics in agriculture, 34, 5-24.

Xie, J.. Qu, X., Shi, J.. \& Sun. D. (2006). Effects of design parameters on flow and temperature fields of a cold store by CFD simulation. Jotirnal of Food Engineering, 77(2), 355-363. 